\title{
Perbandingan Insidensi Hipotensi Saat Induksi Intravena Propofol 2 Mg/Kg Bb Pada Posisi Supine dengan Perlakuan dan Tanpa Perlakuan Elevasi Tungkai
}

\author{
Beni indra ${ }^{1}$, Untung Widodo ${ }^{2}$, Yunita Widyastuti ${ }^{2}$
}

\section{Abstrak}

Penggunaan Propofol untuk induksi pada general anestesi dapat menyebabkan hipotensi akibat vasodilatasi arteri dan vena terutama vena kapasitan ditungkai. Manuver elevasi tungkai dapat mempertahankan stabilitas hemodinamik dengan meningkatkan aliran balik vena ke jantung dan mengurangi penumpukan darah di vena kapasitan tungkai. Penelitian ini dirancang dengan menggunakan cara Open Randomized Control Trial. Subyek penelitian adalah 184 sampel pasien dewasa ASA I-II yang menjalani operasi elektif dengan menggunakan general anestesi dengan induksi propofol. Kelompok sampel penelitian dibagi dalam dua kelompok masing-masing berjumlah 92 orang. Setelah prabeban cairan RL $10 \mathrm{cc} / \mathrm{kgbb}$ dan pemberian fentanyl $2 \mathrm{mcg} / \mathrm{kgbb}$ dan midazolam $0,05 \mathrm{mg} / \mathrm{kgbb}$ maka kelompok A dilakukan elevasi tungkai $45^{\circ}$ satu menit sebelum induksi propofol dan dipertahankan sampai penelitian selesai. Sedangkan kelompok B tidak dilakukan elevasi tungkai. Data yang dikumpulkan dianalisa dengan uji $t$ tes. Untuk data proporsi dilakukan analisa dengan tes chi-square. Dari data demografi tidak didapatkan perbedaan yang bermakna secara statistik $(p>0,05)$ antara kedua kelompok penelitian kecuali untuk BMI $(p<0,05)$. Insidensi hipotensi menit pertama pasca induksi propofol pada kelompok $A$ (elevasi tungkai) secara signifikan lebih rendah (12\%) dibanding kelompok kontrol B $(27,2 \%)(p=0,016 ; p<0,05)$. Pada menit ketiga pasca induksi juga didapatkan insidensi hipotensi kelompok $A \quad(15,2 \%)$ signifikan lebih rendah dibanding kelompok $B(23,9 \%)(p=0,014 ; p<0,05)$. Elevasi tungkai 45 derajat efektif dalam menurunkan insidensi hipotensi pasca induksi propofol.

Kata kunci: propofol, hipotensi, elevasi tungkai

\begin{abstract}
The induction of general anaesthesia with propofol may induce of considerable degree of hypotension that has been atributed to decrease in systemic vascular resistance caused by combination of venous and arterial vasodilatation. It will produce a shifting of blood to venous reservoir, especially capacitance venule of legs. Leg elevation can provide hemodynamic stability by increases cardiac preload and recruits blood contained in the venous reservoir. This is Open Randomized Control Trial include 184 elective surgery patients with American Society of Anaesthesiologist (ASA) physical status I and II. Anesthesia was induced with propofol. Patients were randomly allocated into two groups with 92 patients in each. All the patients received Ringer's Lactate $(10 \mathrm{ml} / \mathrm{kg})$ and premedicated with fentanyl $(2 \mathrm{mcg} / \mathrm{kg})$ and midazolam $(0,05 \mathrm{mg} / \mathrm{kg})$ before induction of anesthesia. Group $A$ was performed passive leg raising 45 degree 1 minute before injection of propofol until the end of study and group $B$ (control) did not receive any maneuver. Parametric data were analyzed with t-test and categorical data was done by using Chi-square test. A p value of less than 0,05 was consider significant. Demografic characteristics (age, sex, body weight and height) and baseline haemodynamic parameters of the patients were similar in two groups $(p>0.05)$ except for BMI $(p<0.05)$. The incidence of hypotension was significantly lower in group $A(12 \%$, ) than group $B$ $(27,2 \%)$ at the first minute after propofol injection, $p$ value $=0.016(p<0,05)$. In the third minute, incidence of hypotension was also significantly lower in group $A(15,2 \%)$ than group $B(23,9 \%), p$ value $=0,014(p<0,05)$. Leg elevation maneuver $45^{\circ}$ significantly decrease incidence of hypotension after propofol induction.
\end{abstract}

Keywords: Propofol, hypotension, leg elevation

Affiliasi penulis : 1. Fakultas Kedokteran Universitas Andalas Padang, 2. Fakultas Kedokteran Universitas Gajah Mada Korespondensi : Beni Indra, drbeniindra@gmail.com Telp: 081371096227

\section{PENDAHULUAN}

Propofol telah digunakan secara luas untuk induksi dan pemeliharaan dalam anestesi umum. Dengan dosis yang direkomendasikan untuk induksi dapat menyebabkan perubahan hemodinamik yang signifikan. Penelitian Sebel dan Lowdon (1989) dalam Uzun et al (2011) memperlihatkan dosis induksi propofol $2 \mathrm{mg} / \mathrm{kgbb}$ menghasilkan penurunan tekanan darah sistolik lebih kurang $30 \%$. $^{1,2}$

Propofol menyebabkan penurunan tekanan darah sistemik yang berkaitan dengan perubahan pada curah jantung dan resistensi vaskuler sistemik. ${ }^{3}$ Penelitian yang dilakukan oleh Muzi et al (1992) menunjukkan propofol mempengaruhi secara langsung otot polos vena sehingga menyebabkan dilatasi di sistem vena. ${ }^{4}$ Pooling darah di vena terutama vena-vena kapasitan berperan penting dalam terjadinya hipotensi sehingga direkomendasikan pemberian cairan 
intravena untuk mengganti defisit cairan dan meminimalkan efek hipotensi selama pemberian propofol. $^{4}$

Hipotensi yang terjadi dapat menyebabkan iskemik miokard pada area yang aliran darahnya telah mengalami stenosis dan juga mempengaruhi perfusi cerebral terutama pasien yang telah mengalami stenosis di arteri intracerebral atau karotis. Hipotensi juga akan mengganggu autoregulasi organ-organ vital yang biasanya dipertahankan dalam rentang MAP (mean arterial pressure) $60-160 \mathrm{mmHg}^{5}$

Ahli anestesi telah berusaha menggunakan beberapa cara untuk mencegah efek hipotensi akibat induksi propofol seperti prabeban cairan, pencegahan dengan obat-obat vasokontriktor dan mengatur kecepatan injeksi propofol namun hasilnya belum memuaskan. Dalam penelitian Rabadi (2013), preloading dengan normal saline 0,9\% sebelum induksi propofol tidak memberikan efek dalam mencegah hipotensi tetapi menurunkan persentase turunnya tekanan darah dibanding kelompok kontrol. $^{5}$ Sedangkan penelitian Imran (2007) penambahan $100 \mu \mathrm{g}$ phenylephrin dapat menurunkan insidensi hipotensi menjadi 20\% tetapi dengan dosis $50 \mu \mathrm{g}$ tidak menurunkan insidensi hipotensi secara bermakna. ${ }^{6}$

Mekanisme terjadinya hipotensi pasca induksi propofol salah satunya karena pooling darah di vena-vena kapasitan tungkai sehingga manuuver elevasi tungkai menjadi hal yang menarik dan sederhana untuk mengembalikan stabilitas hemodinamik.

Penelitian Geerts et al (2012) yang melakukan elevasi tungkai pada pasien syok hipovolemik didapatkan peningkatan curah jantung sebesar $6 \%$ - $9 \%$ dalam satu menit. ${ }^{7}$ Penelitian lainnya oleh Keller et al (2011) yang dilakukan pada pasien pasca bedah jantung dengan ventilasi mekanik di ICU menunjukkan kalau elevasi tungkai secara signifikan meningkatkan Curah jantung $11,1 \%$. $^{8}$

Penelitian yang dilakukan oleh Himawan (2000) di Yogyakarta menunjukkan bahwa elevasi tungkai ternyata efektif menurunkan kejadian hipotensi dalam 20 menit pertama setelah tindakan anestesi spinal. ${ }^{9}$

Dengan adanya beberapa penelitian yang menunjukkan efektifitas elevasi tungkai dapat meningkatkan curah jantung maka penulis ingin meneliti apakah elevasi tungkai dapat menurunkan insidensi hipotensi pasca induksi propofol.

\section{METODE}

Disain penelitian menggunakan Open Randomized Control Trial (uji klinik yang dikontrol secara acak terbuka) dan dilakukan setelah mendapatkan rekomendasi dari Komite Etik Fakultas Kedokteran UGM dan persetujuan tindakan medik (informed consent) dari pasien. ${ }^{10}$ Penelitian dilakukan terhadap pasien-pasien yang menjalani bedah elektif dengan anestesi umum yang menggunakan induksi propofol di RSUP Dr Sardjito Yogyakarta. Kelompok penelitian dibagi dua. Kelompok pertama (A) diberikan perlakuan elevasi tungkai $45^{\circ}$ sebelum induksi propofol $2 \mathrm{mg} / \mathrm{kg} \mathrm{bb}$, sedangkan kelompok kedua (B) tanpa perlakuan elevasi tungkai (kontrol).

Kriteria inklusi meliputi pasien usia 18-16 tahun yang menjalani operasi elektif dengan anestesi umum menggunakan induksi propofol, status fisik ASA I-II, BMI $<30 \mathrm{~kg} / \mathrm{m}^{2}$, Tinggi Badan $140 \mathrm{~cm}-180 \mathrm{~cm}$ dan menyatakan kesediaan untuk mengikuti penelitian. Kriteria eksklusi dari penelitian adalah pasien dengan kontraindikasi diberikan propofol, pasien obstetrik dan operasi jantung, pasien dengan komorbid penyakit jantung, pasien dengan fraktur tungkai bawah dan pasien yang terdiagnosa menderita DVT (deep vein trombosis).

Pada masing-masing pasien diberikan prabeban cairan Ringer Laktat $10 \mathrm{cc} / \mathrm{kg}$ bb dalam $15-20$ menit, premedikasi midazolam $0,05 \mathrm{mg} / \mathrm{kg}$ bb serta fentanyl $2 \mu \mathrm{g} / \mathrm{kg}$ bb. Setelah 1 menit dilakukan pencatatan hasil pengukuran sebagai data awal. Pasien yang terpilih dibagi dua kelompok dengan cara randomisasi, masing-masing kelompok ada 92 pasien. Kelompok A mendapat perlakuan elevasi tungkai $45^{\circ}$ (sampai penelitian selesai) dengan menggunakan alat khusus penumpu kaki. Sedangkan kelompok B tanpa perlakuan elevasi tungkai. Kemudian dilakukan injeksi propofol 2 $\mathrm{mg} / \mathrm{kg}$ bb intravena dalam waktu 30 detik, apa bila sebelum waktu ini pasien sudah terinduksi yang ditandai hilangnya reflek bulu mata maka injeksi propofol dihentikan. Selanjutnya dilakukan pengukuran dan pencatatan hemodinamik (TD, $\mathrm{MAP}, \mathrm{HR}$ dan $\mathrm{SpO}_{2}$ ) menit pertama dan menit ketiga pasca injeksi propofol. Bila terjadi hipotensi diterapi dengan infusan cepat $R L$ dan injeksi efedrin $5 \mathrm{mg}$ intravena. Bila terjadi bradikardi diberikan injeksi Atropin 0,25 mg intravena. Selama penelitian berlangsung, pasien diberikan oksigen tanpa gas anestesi. Setelah penelitian selesai, tindakan anestesi dilanjutkan sesuai prosedur yang ada.

Data dianalisis dengan bantuan program komputer paket program statistik SPSS versi 17.0 for windows. Data parametrik dianalisa dengan $t$-test dan data kategorik dianalisa dengan chi square test. Nilai $p$ kecil dari 0,05 dianggap bermakna secara statistik.

\section{HASIL}

Subyek penelitian ada 184 pasien yang terdiri dari 92 pasien kelompok $A$ yang mendapat perlakuan elevasi tungkai dan 92 pasien kelompok B (kontrol).

Tabel 1 menunjukkan bahwa karakteristik demografi kedua kelompok penelitian tidak berbeda bermakna secara statistik tapi untuk BMl (body mass index) didapatkan nilai $p<0,05$ namun demikian setiap 
sampel penelitian berada dalam nilai BMI normal. Begitu juga dengan parameter hemodinamik awal pasien di bangsal dan hemodinamik pasca sedasi tidak terdapat perbedaan yang bermakna secara statistik pada kedua kelompok $(p>0,05)$.

Tabel 1. Data demografi

\begin{tabular}{|c|c|c|c|}
\hline Variabel & $\begin{array}{l}\text { Kelompok } A \\
\text { mean } \pm S D\end{array}$ & $\begin{array}{l}\text { Kelompok } B \\
\text { mean } \pm S D\end{array}$ & $P$ \\
\hline Umur (tahun) & $42.49 \pm 14.01$ & $41,05 \pm 13.87$ & 0,373 \\
\hline Berat badan $(\mathrm{kg})$ & $53.42 \pm 8.16$ & $55.40 \pm 9.22$ & 0,125 \\
\hline $\begin{array}{l}\text { Tinggi badan } \\
\text { (meter) }\end{array}$ & $1,58 \pm 0,06$ & $1,59 \pm 0,06$ & 0,441 \\
\hline BMI & $21,23 \pm 2,78$ & $22,19 \pm 3,12$ & 0,028 \\
\hline $\begin{array}{l}\text { Panjang tungkai } \\
\text { (cm) }\end{array}$ & $81,66 \pm 3.24$ & $81,65 \pm 3.32$ & 0,982 \\
\hline $\begin{array}{l}\text { Jenis kelamin, } n \\
(\%)\end{array}$ & & & 0,649 \\
\hline Laki-laki & $37(40,2 \%)$ & 33 (35,9\%) & \\
\hline Perempuan & $55(59,8 \%)$ & $59(64,1 \%)$ & \\
\hline $\begin{array}{l}\text { Status Fisik ASA, } \\
\text { n (\%) }\end{array}$ & & & 0,376 \\
\hline ASA 1 & $43(46,7 \%)$ & $50(54,3 \%)$ & \\
\hline ASA 2 & $49(53,3 \%)$ & $42(45,7 \%)$ & \\
\hline
\end{tabular}

Jumlah sampel yang mengalami hipotensi sampai pada menit ketiga penelitan adalah 25 sampel $(27,2 \%)$ untuk kelompok elevasi tungkai sedangkan pada kelompok kontrol 47 sampel (51,1\%). Dengan analisa chi square didapatkan nilai $p=0,002(p<0,05)$. Pengamatan menit pertama pasca injeksi propofol didapatkan kelompok elevasi tungkai yang mengalami hipotensi 11 sampel (12\%), sedangkan kelompok kontrol terdapat 25 sampel $(27,2 \%)$. Analisa statistik didapatkan nilai $p=0,016$ $(p<0,05)$.

Pengamatan pada menit ketiga pasca injeksi propofol didapatkan pada kelompok elevasi tungkai yang mengalami hipotensi 21 sampel $(22,8 \%)$ dengan rincian 14 sampel $(15,2 \%)$ merupakan kasus baru dan 7 sampel $(7,6 \%)$ merupakan lanjutan hipotensi dari menit pertama yang dalam proses resusitasi. Pada kelompok kontrol terdapat 39 sampel (42,4\%) yang mengalami hipotensi dengan rincian 22 sampel (23,9\%) kasus baru dan 17 sampel $(18,5 \%)$ lanjutan hipotensi dari menit pertama yang dalam proses resusitasi. Nilai $p=$ $0,014(p<0,05)($ tabel 2 dan gambar 1$)$

Tabel 2. Insidensi hipotensi sampai menit ke-3 penelitian.

\begin{tabular}{llll}
\hline $\begin{array}{l}\text { Kelompok } \\
\text { Penelitian }\end{array}$ & \multicolumn{2}{l}{ Kejadian Hipotensi } & $\boldsymbol{P}$ \\
& Ya (\%) & Tidak (\%) & \\
& & & \\
& & & \\
\hline Elevasi & 25 & 67 & 0,002 \\
Tungkai & $(27,2 \%)$ & $(72,8 \%)$ & \\
Kontrol & 47 & 45 & \\
& $(51,1 \%)$ & $(48,9 \%)$ &
\end{tabular}

Keterangan : Hasil dalam proporsi (\%), $p<0,05=$ berbeda bermakna secara statistik

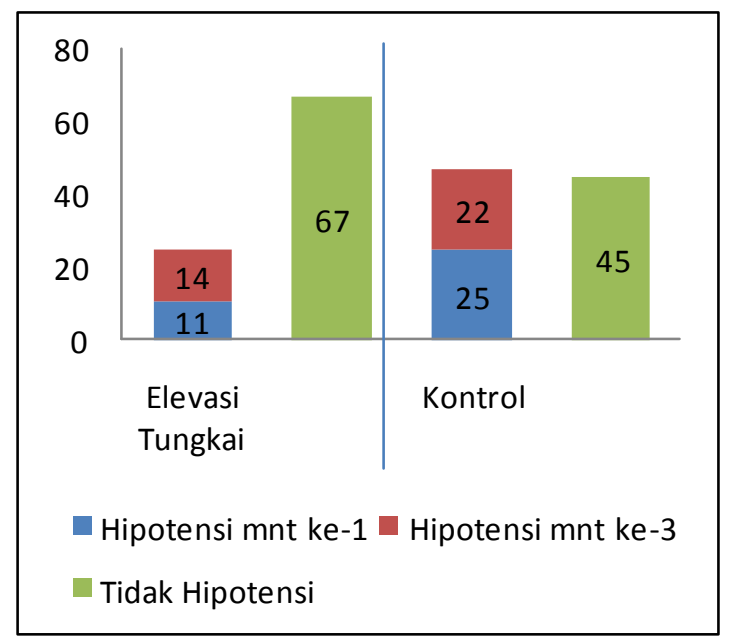

Gambar 1. Insidensi hipotensi sampai menit ke-3 penelitian.

Pengamatan pada menit pertama dan ketiga pasca induksi propofol memperlihatkan penurunan TD rata-rata pada kedua kelompok berbeda bermakna $(p<0,05)$, sedangkan terhadap laju nadi dan saturasi perifer $\mathrm{O} 2$ tidak didapatkan perbedaan yang bermakna diantara kedua kelompok penelitian $(p>0,05)$ (tabel 3$)$. 
Tabel 3. Data rata-rata hemodinamik pasien pasca sedasi dan menit pertama serta menit ketiga pasca induksi propofol

\begin{tabular}{|c|c|c|c|c|c|c|}
\hline \multirow{3}{*}{ Variabel } & \multicolumn{2}{|c|}{ Pasca Sedasi } & \multicolumn{2}{|c|}{$1 \mathrm{mnt}$ pasca induksi propofol } & \multicolumn{2}{|c|}{$3 \mathrm{mnt}$ pasca induksi propofol } \\
\hline & Perlakuan (A) & Kontrol (B) & 'erlakuan (A) & íontrol (B) & Perlakuan (A) & Kontrol (B) \\
\hline & mean $\pm S D$ & mean $\pm S D$ & nean \pm SD & nean $\pm S D$ & mean $\pm S D$ & mean $\pm S D$ \\
\hline TD Sistolik (mm Hg) & $129,72 \pm 16,24$ & $129,43 \pm 13,53$ * & $18,79 \pm 19,20$ & $12,83 \pm 14,38 \uparrow$ & $114,05 \pm 19,19$ & $106,23 \pm 12,52 \uparrow$ \\
\hline TD Diastolik (mm Hg) & $78,71 \pm 11,10$ & $77,91 \pm 10,61^{*}$ & $6,65 \pm 12,08$ & $i 9,23 \pm 10,51 \uparrow$ & $69,71 \pm 12,31$ & $65,89 \pm 11,15 \uparrow$ \\
\hline $\mathrm{MAP}(\mathrm{mm} \mathrm{Hg})$ & $95,71 \pm 11,42$ & $95,07 \pm 10,28^{*}$ & $38,03 \pm 13,69$ & $33,75 \pm 11,32 \uparrow$ & $84,47 \pm 13,82$ & $79,34 \pm 10,83 \uparrow$ \\
\hline Laju Jantung ( x /mnt) & $85,77 \pm 11,94$ & $86,67 \pm 12,82^{*}$ & $32,10 \pm 12,53$ & $' 9,74 \pm 10,55^{\star}$ & $79,61 \pm 11,89$ & $80,68 \pm 11,25$ * \\
\hline $\mathrm{SpO}_{2}(\%)$ & $98,92 \pm 1,21$ & $99,14 \pm 0,98$ * & $19,23 \pm 0,99$ & $19,49 \pm 0,76 \uparrow$ & $99,46 \pm 0,84)$ & $99,60 \pm 0,63^{*}$ \\
\hline
\end{tabular}

Keterangan : Hasil dalam mean $\pm \mathrm{SD}, \mathrm{p}<0,05=$ berbeda bermakna secara statistik.

* : Nilai $p$ untuk t- test antara kelompok $A$ dan $B>0,05$

† : Nilai $p$ untuk t- test antara kelompok $A$ dan $B<0,05$

\section{DISKUSI}

Data demografi pasien pada kedua kelompok penelitian tidak didapatkan perbedaan yang bermakna secara statistik $(p>0,05)$ dengan demikian data karakteristik pasien dapat dikatakan homogen (setara) dan layak untuk dibandingkan dalam penelitian ini.

Insidensi hipotensi selama penelitian berlangsung pada kelompok elevasi tungkai adalah 25 sampel $(27,2 \%)$ sedangkan pada kelompok kontrol ada 47 sampel $(51,1 \%)$. Perbedaan ini bermakna secara statistik dengan nilai $p=0,014(p<0,05)$. Penelitian ini menegaskan efektifitas elevasi tungkai dalam menurunkan insidensi hipotensi pasca induksi propofol. Sedangkan terhadap penurunan laju nadi dan saturasi perifer $\mathrm{O} 2$ tidak didapatkan perbedaan pada kedua kelompok penelitian $(p>0,05)$.

Penelitian ini juga menegaskan bahwa induksi propofol menyebabkan penurunan tekanan darah arteri secara signifikan. Data ini sejalan dengan penelitian Rabadi (2012) yang meyimpulkan induksi propofol menyebabkan penurunan tekanan darah dan laju nadi.5

Elevasi tungkai dalam menurunkan insidensi hipotensi pasca induksi propofol tidak seefektif dibandingkan pasca anestesi spinal. Penelitian Himawan (2000) memperlihatkan elevasi tungkai efektif mencegah hipotensi pasca anestesi spinal sampai akhir pengamatan (menit ke-20) penelitian.9 Perbedaan efek dari elevasi tungkai pada penenilitian ini dapat dijelaskan karena perbedaan metode anestesi yang digunakan. Pada anestesi umum yang menggunakan induksi propofol terjadi vasodilatasi vaskuler hampir di seluruh vena dan arteri tubuh sedangkan pada anestesi spinal terlokalisir pada area yang diblok terutama di daerah. Secara umum elevasi tungkai akan meningkatkan preload dan kapasitas kardiak namun dengan induksi propofol terjadi depresi miokard yang akan menekan reflek kardiovaskuler dan modifikasi vaskuler regional.

Selama penelitian dilakukan terhadap 184 sampel tidak didapatkan kejadian seperti syok dan aritmia, hal ini karena dari awal penelitian telah dipilih pasien dengan kondisi sehat atau dengan gangguan sistemik ringan. Sampel penelitian juga telah mendapat prabeban cairan kristaloid untuk mengganti defisit cairan akibat puasa sebelum dilakukan induksi propofol. Faktor lainnya adalah dengan mengatur kecepatan injeksi propofol. Semua faktor tadi berpengaruh terhadap stabilitas hemodinamik pasca induksi propofol.

Ada beberapa kelemahan dalam penelitian ini yaitu dalam mengontrol perlakuan yang sama terhadap ventilasi pasien pasca induksi propofol meskipun dalam cara kerja telah ditekankan untuk melakukan normo ventilasi.. Hal lainnya adalah penilaian status cairan pasien menjelang induksi. Penggantian defisit cairan hanya berdasarkan lama puasa tanpa menggunakan monitor invasif sedangkan sebagian dari sampel penelitian dengan alasan medis ada yang sudah terpasang infus di ruangan dan mendapatkan pengobatan selama puasa.

\section{KESIMPULAN}

Elevasi tungkai 45 efektif menurunkan insidensi hipotensi pasca induksi propofol $2 \mathrm{mg} / \mathrm{kg}$ bb i.v. menjadi 25 sampel $(27,2 \%)$ dibanding pada kelompok kontrol 47 sampel $(51,1 \%)$. nilai $p=0,002$ ( $p<0,05)$.

\section{DAFTAR PUSTAKA}

1. Sebel P.S., Lowdon J.D., Propofol, a new intravenous anaesthetic, Annaesthesiology, 1989; 71: 260-77.

2. Uzun S., Ozkaya B.A., Yilbas O.S., Ayhan B., Sahin A., Aypar U., Effects of different propofol 
injection speeds on blood pressure, dose, and time of induction, Turk J Med Sci, 2011; 41 (3): 397-401.

3. Stoelting R.K., Hillier S.C., Pharmacology \& Physiology in Anesthetic Practice, $4^{\text {th }}$ ed, Philadelphia: Lippincott Williams \& Wilkins, 2006.

4. Muzi M., Barens R.A., Kampine J.P., Ebert T.J., Venodilation Contributes to propofol-mediated Hypotension in Humans, Anesth Analg, 1992;74:877-83.

5. Rabadi D., Effect of Normal Saline administration on circulation stability during general anesthesia induction with propofol in gynecological procedures - Randomised-controlled study, Rev Bras Anestesiol, 2013;63(3):258-261.

6. Imran M., Khan F.H., Khan M.A., Attenuation of hypotension using phenylephrine during induction of anesthesia, Journal of Pakistan Medical Association, 2007 ,

57:543.
7. Geerts B.F., Bergh L.V.D., Stijnen T., Aarts L.P.P.H.J., Jansen J.R.C., Comprehensive review: is it better to use the Trendelenberg position or passive leg raising for initial treatment of hypovolemia?, Journal of Clinical Anesthesia, 2012 ; 24 : 668-674.

8. Keller G., Desebbe O., Benard M., Bouchet J.P., Lehot J.J., Bedside assessment of passive leg raising effects on venous return, Journal of Clinical Monitoring and Computing (2011), 25: 257-263.

9. Himawan A., Pengaruh elevasi tungkai dalam mencegah hipotensi pada spinal anestesi sampai menit ke 20, Karya tulis ilmiah, Yogyakarta, 2000.

10. Sastroasmoro S., Ismael S., Pemilihan subyek penelitian, Dasar-Dasar Metodologi Penelitian Klinis, Edisi ke-3, Jakarta : Sagung Seto, 2011: 67-76. 